\title{
Bone resorption by cells isolated from rheumatoid synovium
}

\author{
J S Chang, J M Quinn, A Demaziere, C J Bulstrode, M J Francis, R B Duthie, N A Athanasou
}

\begin{abstract}
Cellular mechanisms accounting for the osteolysis of rheumatoid erosions are poorly understood. Cells were isolated and characterised from the synovium of 16 patients with rheumatoid arthritis (RA) and four patients with osteoarthritis and their ability to resorb bone was assessed using a scanning electron microscope bone resorption assay. Macrophages were the major cell type isolated from the synovium of patients with RA. These produced extensive roughening of the bone surface without resorption pit formation. This low grade type of bone resorption was not affected by systemic (calcitonin, parathyroid hormone, 1,25-dihydroxyvitamin $\mathrm{D}_{3}$ ) or local (interleukin 1, prostaglandin $E_{2}$ ) factors influencing bone resorption. Macrophage mediated bone resorption differs qualitatively and quantitatively from that of osteoclasts but is likely to play an important part in the development of marginal erosions in RA.
\end{abstract}

(Ann Rheum Dis 1992; 51: 1223-1229)

One of the major pathological changes in rheumatoid arthritis (RA) is the formation of pannus, exuberant granulation tissue which extends from the synovial/cartilage interface over the surface of the articular cartilage, leading to its consequent destruction and erosion. ${ }^{1}$ Pannus also extends into subchondral bone, producing marginal erosions and cyst-like areas of bone destruction. The inflamed synovium from which pannus develops is rich in inflammatory cells, including lymphocytes, plasma cells, and numerous macrophages. In RA there is also hyperplasia of the synovial intima, the synovial lining cells being almost entirely of the macrophage phenotype. ${ }^{2-4}$ Collections of inflammatory cells, similar in type to those seen in the rheumatoid synovium, are also found in the epiphysial bone and, with osteoclasts, may be associated with active bone destruction. $^{1}$

Release of lysosomal enzymes, including various types of proteinases, by rheumatoid inflammatory cells has been proposed to account for the destruction of cartilage and other articular connective tissues. ${ }^{56}$ Cytokines, prostaglandins, and other local factors play a major part in cell-cell interactions that lead to the release of these enzymes. ${ }^{5} 6$ Prostaglandins and several cytokines, such as interleukin 1, are also known to be potent stimulators of bone resorption. ${ }^{78}$ Macrophages are known to produce and respond to these mediators which stimulate bone resorption and are a major source of proteinases. ${ }^{9}$ There is much indirect evidence to show that macrophages, including their fused products, macrophage polykaryons, are capable of degrading the organic and mineral components of bone. ${ }^{10} 11$ Using scanning electron microscopy, direct evidence of bone resorption by macrophages derived from extraskeletal tissues has also been noted. ${ }^{12} 13$

The precise role of macrophages in the formation of marginal erosions in RA is uncertain. It has not been determined whether macrophages in inflammatory pannus contribute to the bone resorption of marginal erosions by stimulating osteoclastic bone resorption or whether they can, in some measure, directly resorb bone. This study atempts to define the cells in the rheumatoid synovium which are capable of resorbing bone. We have isolated phagocytes from the synovium of patients with RA (with patients with osteoarthritis (OA) as controls) and characterised these cells cytochemically and immunocytochemically. Their ability to resorb bone in the presence and absence of systemic (parathyroid hormone, vitamin $\mathrm{D}_{3}$ ) and local (prostaglandin, interleukin 1)hormonal stimulators of bone resorption has also been determined directly by scanning electron microscopy.

\section{Patients and methods}

Synovial tissue was obtained fresh from 16 patients with seropositive $\mathrm{RA}^{14}$ and four patients with $\mathrm{OA}$ during operations. The synovial samples from patients with RA were obtained from four hip joints, two knee joints, five elbow joints, and five wrist joints; 14 women and two men were studied and the average age was 50 years (range 30-65). The four synovial samples from patients with $\mathrm{OA}$ were all derived from the hip joint and were from patients aged 59, 65, 68 , and 69 years.

The synovia were immediately placed into Hanks's balanced salt solution (HBSS) (Gibco, UK). Specimen radiographs of the synovium were taken to determine if there was any calcific debris or bone particles within the synovial membrane. Patients showing radiographically detected calcification of the synovial membrane were excluded from the study. Blocks of synovium were taken for routine histologic study. The remainder of the sample was used for the extraction of cells for in vitro culture.

CORTICAL BONE SLICE PREPARATION FOR SCANNING ELECTRON MICROSCOPE BONE RESORPTION ASSAY

Blocks of cortical bone were obtained from the 
femoral midshaft of patients at necropsy. Adherent soft tissues were removed, then the block was cut longitudinally into bone slices (about $1.0 \times 1.0 \times 0.3 \mathrm{~cm}$ ) with a low speed bone saw using a diamond wheel (Buehler, Isomet, IL, USA). The bone slices were treated with ultrasound for 15 minutes in sterile distilled water, washed in acetone and ethanol, and then stored dry at room temperature.

\section{PREPARATION OF MACROPHAGE CULTURES}

The synovium was cut into small pieces (about 1-2 $\mathrm{mm}$ ) and washed thoroughly in HBSS. The synovial fragments were digested for two hours at $37^{\circ} \mathrm{C}$ in $\mathrm{HBSS}$ containing $1 \mathrm{mg} / \mathrm{ml}$ collagenase Type I (Sigma, UK). The supernatant was carefully collected and resuspended in $10 \mathrm{ml}$ HBSS. This was twice centrifuged at 1200 $\mathrm{rev} / \mathrm{min}$ for 10 minutes. Finally, the cell pellet was resuspended in $5 \mathrm{ml}$ of $\alpha$ minimal essential medium (MEM; Gibco) with $10 \%$ fetal calf serum (Gibco) containing glutamine, benzyl penicillin, and streptomycin (MEM/FCS). The cell suspension was added to the bone slices and to $6 \mathrm{~mm}$ glass coverslips in $7 \mathrm{~mm}$ diameter multiwell plates (Nunclon, Denmark). Cell suspension $(100 \mu \mathrm{l})$ was placed into each well and settled for one hour on the bone slices and coverslips at $37^{\circ} \mathrm{C}$ and $5 \%$ carbon dioxide. Coverslips and bone slices were removed and washed vigorously in MEM then placed in fresh wells containing $250 \mu$ l culture medium with or without added hormones. Approximately 1000 cells derived from synovial samples from patients with RA and 400 cells from synovium from patients with OA remained adherent to the coverslips after this isolation procedure. Added hormones and final concentrations were parathyroid hormone (NIBSC), $10 \mathrm{IU} / \mathrm{ml} ; 1,25-$ dihydroxyvitamin $\mathrm{D}_{3}$ (Roche, UK), $1 \times 10^{8} \mathrm{~mol} / \mathrm{l}$; salmon calcitonin (Rorer, UK), $1 \mu \mathrm{g} / \mathrm{ml}$ prostaglandin $E_{2}$ (Sigma) $1 \times 10^{-6} \mathrm{~mol} / \mathrm{l}$, interleukin $1 \alpha(20 \mathrm{ng} / \mathrm{ml}), 20 \mathrm{ng} / \mathrm{ml}$. Cells were incubated on bone slices and coverslips for periods of 24 hours, three days, seven days, 14 days, 21 days or 28 days, the medium being changed every three days. For each synovial specimen, six to eight bone slices were examined at each time interval. In cultures incubated for periods of 24 hours, three days, and seven days, two bones were fixed in $4 \%$ glutaraldehyde in $0.2 \mathrm{M}$ cacodylate buffer for two hours. ${ }^{12}{ }^{13}$ The remainder of the bone slices in these and longer cultures were placed in aqueous ammonia solution for two hours and then ultrasonicated in tap water. This treatment removes the cells from the bone surface and allows the underlying substrate to be examined for evidence of surface resorption or resorption pit formation. Specimens were dehydrated in a graded ethanol series and dried at their critical point using carbon dioxide. After sputtering with gold they were examined in a Philips SEM 505 scanning electron microscope. The number of resorption pits was counted on the ammonia treated bone slices and evidence of surface roughening recorded.

\section{CYTOCHEMICAL AND IMMUNOCYTOCHEMICAL}

CHARACTERISATION OF ISOLATED CELLS

Cells isolated and cultured on coverslips were incubated in MEM/FCS for the time given in the preceding section. One of the coverslips was then fixed in formalin and stained with toluidine blue for two minutes to show the cell morphometry. Cell cultures on coverslips were also fixed in cold acetone and stained for macrophage and osteoclast associated enzyme activity, acid phosphatase, and tartrate resistant acid phosphatase using a kit from Sigma. ${ }^{15}$

The isolated cells were also characterised immunohistochemically. After incubation for 24 hours the cell cultures on the coverslips were fixed by acetone then stained by an indirect immunoperoxidase technique for the detection of several macrophage/osteoclast associated antigens. ${ }^{16}$ The monoclonal antibodies used were derived from the IVth International Workshop on Human Leucocyte Differentiation Antigens ${ }^{17}$ (table 1).

\section{RESPONSE TO CALCITONIN}

After digestion the cell suspension was added to the wells of a $17 \mathrm{~mm}$ diameter Costar plate containing $16 \mathrm{~mm}$ glass coverslips. Cells were incubated for 20 minutes at $37^{\circ} \mathrm{C}$ in $5 \%$ carbon dioxide. The coverslips were then removed from these wells and washed vigorously to remove non-adherent cells. One of a pair of coverslips was then placed in a well containing tissue culture medium (MEM/FCS) with calcitonin $(1 \mu \mathrm{g} / \mathrm{ml})$ and the other in medium alone. The cells were incubated for up to one hour and continuously observed for a morphological response to calcitonin. ${ }^{18}$ They were then

Table 1 Monoclonal antibodies used in this study and results of staining. All the antibodies (except CR3/43) derived from the 4 th international workshop on human leucocytes differentiation antigens ${ }^{17}$

\begin{tabular}{|c|c|c|c|c|c|c|}
\hline \multirow{2}{*}{$\begin{array}{l}\text { Monoclonal } \\
\text { antibody }\end{array}$} & \multirow[t]{2}{*}{ Source } & \multirow{2}{*}{$\begin{array}{l}\text { Macrophage/ } \\
\text { osteoclast } \\
\text { associated } \\
C D \text { antigen }\end{array}$} & \multicolumn{2}{|l|}{24 hours } & \multicolumn{2}{|l|}{7 days } \\
\hline & & & $\begin{array}{l}\text { Mononuclear } \\
\text { cells }\end{array}$ & $\begin{array}{l}\text { Multinucleated } \\
\text { cells }\end{array}$ & $\begin{array}{l}\text { Mononuclear } \\
\text { cells }\end{array}$ & $\begin{array}{l}\text { Multinucleated } \\
\text { cells }\end{array}$ \\
\hline \multirow{5}{*}{$\begin{array}{l}\text { MHM24 } \\
\text { MHM23 } \\
90 \cdot 3 \\
\text { CLB Mon/1 } \\
80 \cdot 2 \\
\text { F10.89-4 } \\
\text { EBM/11 } \\
\text { Y1/82a } \\
\text { CR3/43 }\end{array}$} & $\begin{array}{l}\text { McMichael } \\
\text { McMichael }\end{array}$ & CD11a/18 & + & - & + & + \\
\hline & $\begin{array}{l}\text { Kraft } \\
\text { Tetteroo }\end{array}$ & CD14* & + & - & + & + \\
\hline & $\begin{array}{l}\text { Kraft } \\
\text { Dalchau }\end{array}$ & $\mathrm{CD}^{2} 5^{*} \dagger$ & + & + & + & + \\
\hline & McGee & $\mathrm{CD}^{\circ} 8^{*} \dagger$ & + & + & + & + \\
\hline & $\begin{array}{l}\text { Mason } \\
\text { Dakopatts }\end{array}$ & HLA-DR* & + & - & + & + \\
\hline
\end{tabular}

*CD antigen present on macrophages but not osteoclasts.

tCD antigen present on macrophages and osteoclasts. ${ }^{16}$ 
Table 2 Number of lacunar resorption pits on bone slices cultured with cells derived from synovium of patients with rheumatoid arthritis $(R A)$ and osteoarthritis (OA). Mean (SEM) number of resorption pits

\begin{tabular}{|c|c|c|c|}
\hline & $R A(n=12)$ & $R A^{*}(n=4)$ & $O A(n=4)$ \\
\hline $\begin{array}{l}\text { Three days of culture } \\
\text { Control } \\
\text { Parathyroid hormone } \\
\text { 1,25-Dihydroxyvitamin } \mathrm{D}_{3} \\
\text { Prostaglandin } \mathrm{E}_{2} \\
\text { Interleukin } 1 \alpha \\
\text { Calcitonin }\end{array}$ & $\begin{array}{l}\mathbf{0} \\
\mathbf{0} \\
\mathbf{0} \\
\mathbf{0} \\
\mathbf{0} \\
\mathbf{0}\end{array}$ & $\begin{array}{l}1.27(0.93) \\
1.38(1.05) \\
1.06(0.74) \\
1.29(0.89) \\
0.98(0.61) \\
0.85(0.70)\end{array}$ & $\begin{array}{l}1.35(0.95) \\
1.86(0.97) \\
1.29(0.69) \\
\mathrm{ND} \ddagger \\
\mathrm{ND} \\
1.59(0.84)\end{array}$ \\
\hline $\begin{array}{l}\text { Seven days } \dagger \\
\text { Control } \\
\text { Parathyroid hormone } \\
\text { 1,25-Dihydroxyvitamin } D_{3} \\
\text { Prostaglandin } E_{2} \\
\text { Interleukin } 1 \alpha \\
\text { Calcitonin }\end{array}$ & $\begin{array}{l}\mathbf{0} \\
\mathbf{0} \\
\mathbf{0} \\
\mathbf{0} \\
\mathbf{0} \\
\mathbf{0}\end{array}$ & $\begin{array}{l}3 \cdot 19(1 \cdot 32) \\
2 \cdot 17(1 \cdot 25) \\
2 \cdot 54(1 \cdot 27) \\
3 \cdot 29(1 \cdot 39) \\
1.09(0 \cdot 84) \\
2 \cdot 86(1 \cdot 36)\end{array}$ & $\begin{array}{l}2.87(1.03) \\
3.19(1.23) \\
3.76(1.54) \\
\text { ND } \\
\text { ND } \\
2 \cdot 56(1 \cdot 19)\end{array}$ \\
\hline $\begin{array}{l}14 \text { days } \\
\text { Control } \\
\text { Parathyroid hormone } \\
\text { 1,25-Dihydroxyvitamin } \mathrm{D}_{3} \\
\text { Prostaglandin } \mathrm{E}_{2} \\
\text { Interleukin } 1 \alpha \\
\text { Calcitonin }\end{array}$ & $\begin{array}{l}0 \\
0 \\
0 \\
0 \\
0 \\
0\end{array}$ & $\begin{array}{l}3.64(1.32) \\
2.49(1.44) \\
2.61(1.40) \\
3.72(1.71) \\
2.81(0.96) \\
2.15(1.06)\end{array}$ & $\begin{array}{l}3.01(1 \cdot 72) \\
2.31(0.97) \\
2.64(1.41) \\
\text { ND } \\
\text { ND } \\
3.64(1.21)\end{array}$ \\
\hline
\end{tabular}

${ }^{*}$ Four RA synovia derived from hips/knees containing bone particles.

† Surface roughening increased in seven and 14 day cultures from $R A$ and $R A^{*}$ synovia. $\ddagger N D=$ not determined.

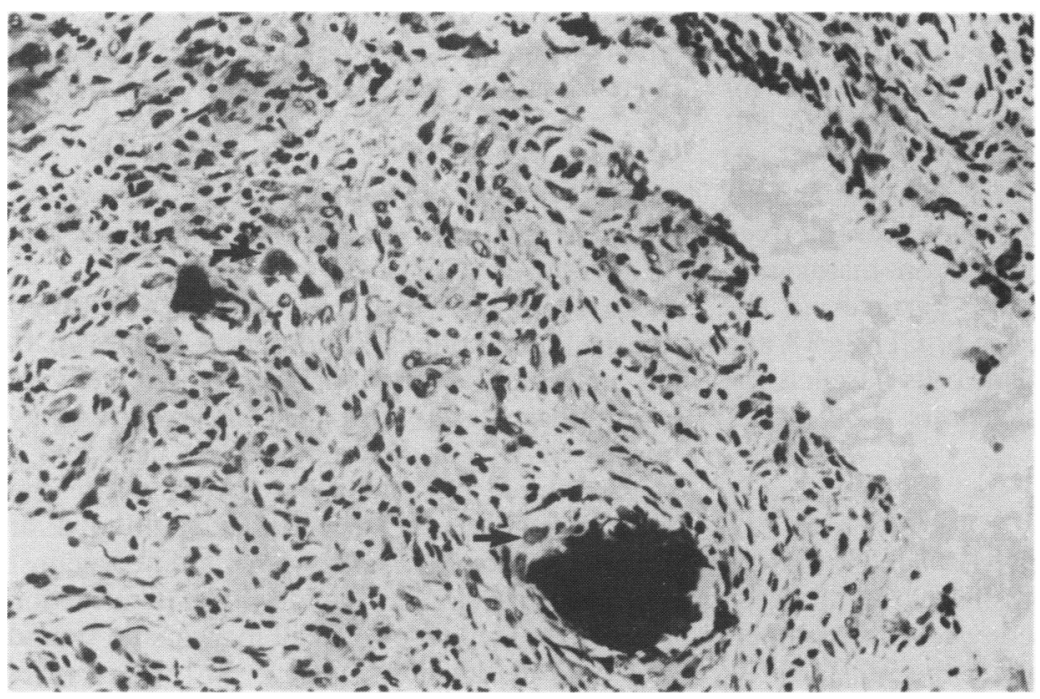

Figure 1 Synovial membrane from the knee of a patient with rheumatoid arthritis showing inflamed subintima with embedded bone fragments and surrounding cellular (including giant cell) response (arrow). Haematoxylin-eosin stain.

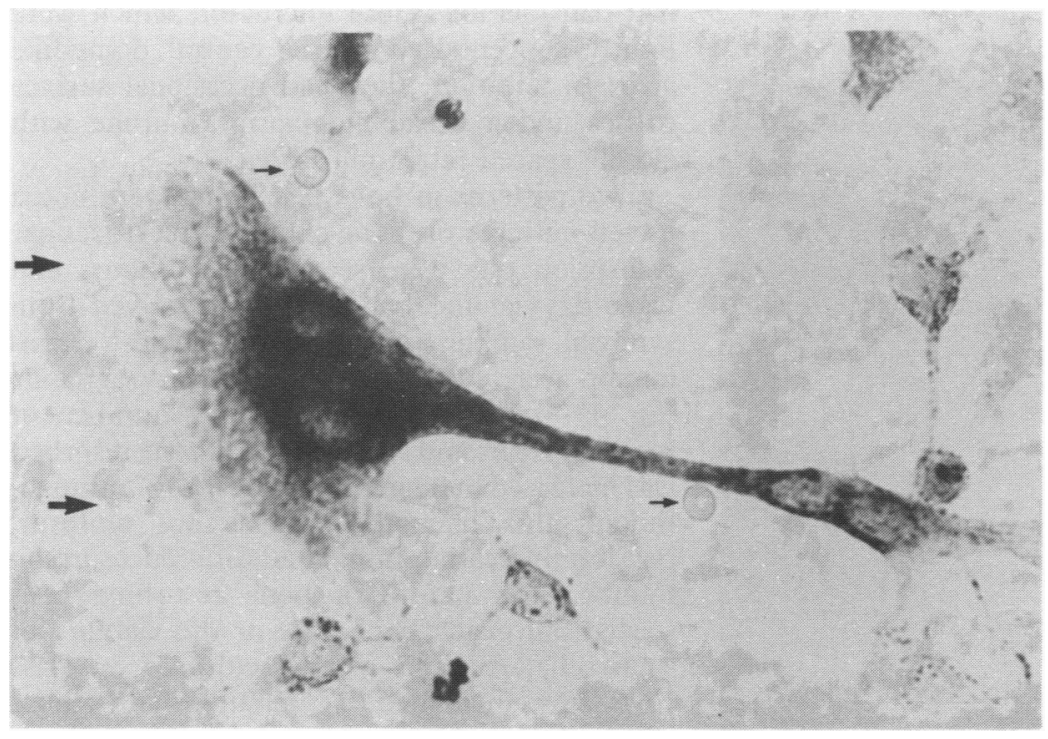

Figure 2 Tartrate resistant acid phosphatase positive multinucleated cell in 24 hour culture. This shows a broad cytoplasmic outline (large arrows) indicating that the cell is motile. Note also unstained mononuclear cells below and at right, as well as red cells (small arrows). fixed in formalin for toluidine blue staining. Evidence of a response to calcitonin was also sought with cells incubated on pairs of coverslips for 24 hours in MEM/FCS.

\section{Results}

\section{HISTOLOGY AND CYTOCHEMISTRY/}

IMMUNOCYTOCHEMISTRY OF CELLS IN SYNOVIAL MEMBRANES FROM PATIENTS WITH ARTHRITIS

The rheumatoid synovial membrane showed typical features of RA with intimal hyperplasia, fibrin exudation, and a heavy subintimal chronic inflammatory infiltrate including occasional lymphoid aggregates. Synovial specimens from patients with OA contained no evidence of a heavy subintimal chronic inflammatory infiltrate. In the two specimens of synovium from patients with $\mathrm{OA}$ and four specimens from patients with RA (indicated by an asterisk in table 2), fragments of bone often surrounded by large mononuclear or osteoclast-like giant cells were noted histologically in the synovial membrane (fig 1).

After 24 hours in culture cells derived from synovium from patients with $\mathrm{RA}$ and $\mathrm{OA}$ showed a similar morphology, being composed of small, spindle shaped cells of fibroblast-like morphology and small, round cells of macrophage-like morphology. Many macrophage-like mononuclear cells were found in cultures derived from synovium from patients with RA. In addition, there were a few larger mononuclear cells of macrophage-like morphology and occasional giant cells, both with abundant cytoplasm. The giant cells isolated from synovium which contained microscopic bone and calcific deposits were osteoclast-like and contained from two to 10 nuclei; they were always found in those cultures which produced lacunar bone resorption and were absent from those cell cultures derived from RA synovium which did not produce resorption pits in the scanning electron microscope bone resorption assay. With increasing time of incubation there was proliferation of fibroblast-like cells which completely covered the coverslip and bone slice surfaces making it difficult to observe the number or activity of other cell types.

Staining of cell cultures for acid phosphatase and tartrate resistant acid phosphatase activity after 24 hours of incubation showed that most $(>90 \%)$ of the adherent round mononuclear cells were positive for acid phosphatase. A few isolated $(<1 \%)$ mononuclear cells positive for tartrate resistant acid phosphatase were found in 24 hour cultures but most were negative for tartrate resistant acid phosphatase. In those cell cultures derived from synovium containing bone debris, multinucleated cells positive for tartrate resistant acid phosphatase were also present (fig 2). Using acid phosphatase and tartrate resistant acid phosphatase staining, it was possible to identify macrophages and giant cells in later cultures despite the fact that they were covered with fibroblasts. Acid phosphatase positive but tartrate resistant acid phosphatase negative multinucleated cells were first seen after three days in culture and increased in number with increasing time of incubation. 


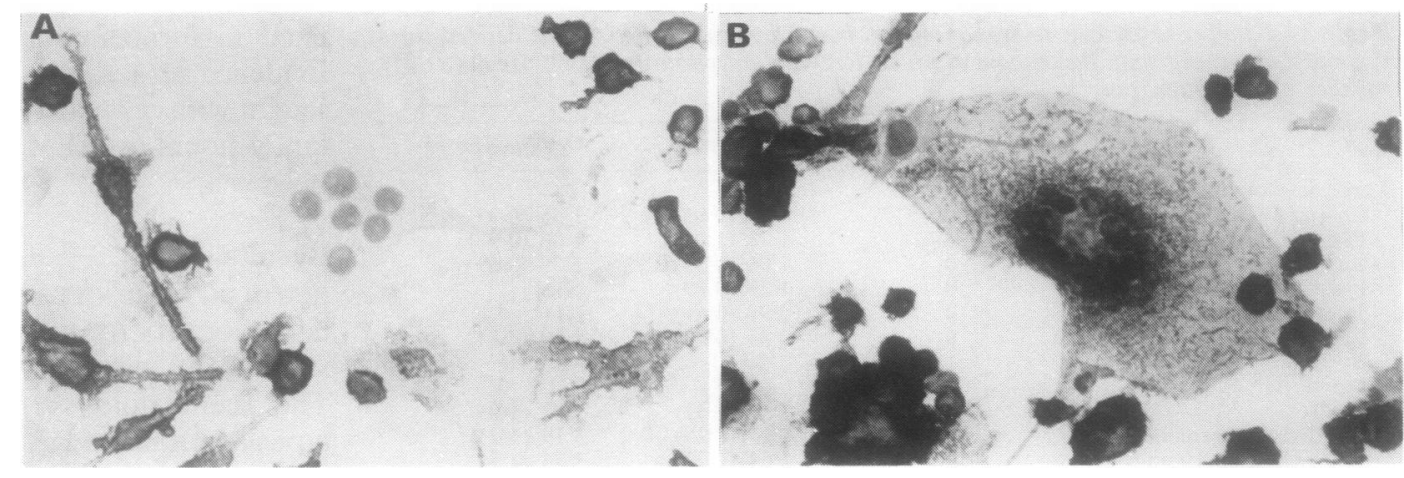

Figure 3 (A) Combined immunohistochemistry and calcitonin response test on cells one hour after isolation from the synovium of a patient with rheumatoid arthritis (shown in fig 1 ). This shows a positive reaction for HLA-DR on most mononuclear cells but no staining of osteoclasts (centre). The osteoclasts show a positive calcitonin response with the retraction of cytoplasmic processes. (B) Macrophage polykaryon (centre) derived from the same cell preparation as in $(A)$ showing broad cytoplasmic outline unaffected by calcitonin and a positive reaction for HLA-DR. Acetone fixation: indirect immunoperoxidase staining.

There was a variable but distinct tendency for mononuclear and multinucleated cells which remained in culture for more than seven days to become positive for tartrate resistant acid phosphatase.

Immunocytochemical staining of the isolated cells showed that all rounded and some spindle shaped mononuclear cells were positive for CD14, CD45, CD11a/18, CD68, and HLA-DR (fig 3). The few osteoclast-like giant cells present in initial cell isolates did not express CD11a/18 or CD14 (fig 3); these were derived from synovial samples which, on histological examination, contained bone particles in the synovial membrane. Absence of CD11a/18 and CD14 antigens on these giant cells parallels the antigenic phenotype of osteoclasts. ${ }^{16}$

\section{RESPONSE TO CALCITONIN}

Mononuclear and giant cells isolated from the synovium onto glass coverslips were observed by phase contrast microscopy to increase their cell area rapidly after settling, the cells quickly expanding their cytoplasm to produce a broad cellular outline. Following the addition of calcitonin, mononuclear cells continued to remain motile and showed no morphological

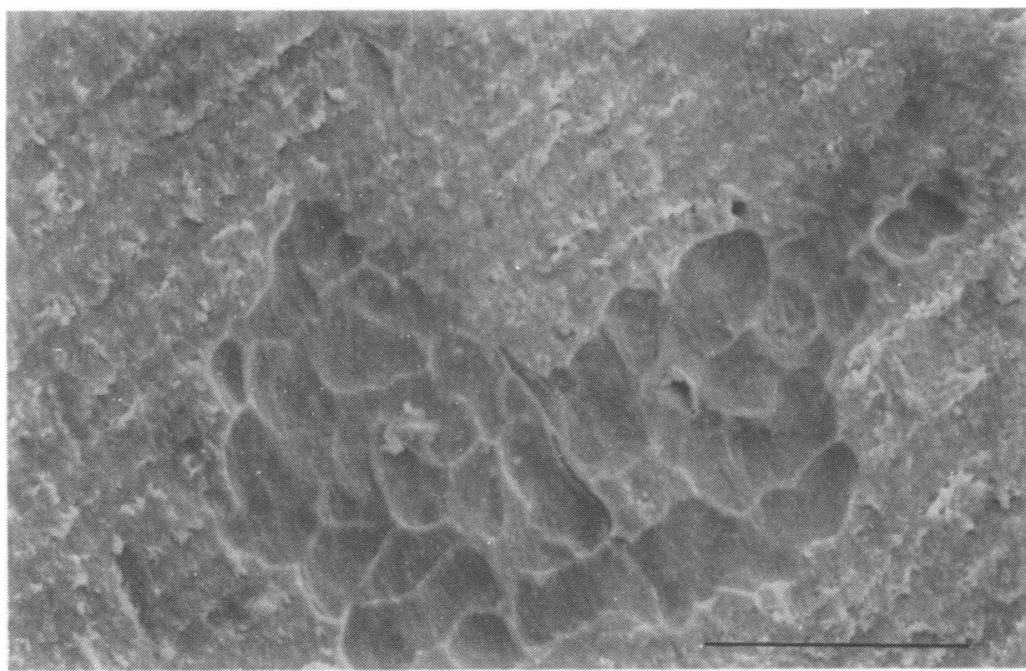

Figure 4 Large well defined compound resorption pit on cortical bone surface seen after three days of incubation of cells isolated from synovium shown in fig 1 . Bar $=500 \mu \mathrm{m}$. response to calcitonin. In some isolates, however, all derived from synovia containing bone fragments, a few giant cells showed an osteclast-like response to calcitonin, becoming immotile with retraction of cytoplasmic pro$\operatorname{cesses}^{18}$ (fig $3 \mathrm{~A}$ ). Identical results were seen after giving calcitonin to cell cultures incubated for 24 hours on glass coverslips.

CELL CULTURES ON BONE SLICES AND EVIDENCE OF BONE RESORPTION SEEN USING A SCANNING ELECTRON MICROSCOPE

Bone slices on which cells had been cultured for 24 hours contained numerous small (up to $20 \mu \mathrm{m}$ ), round and spindle shaped cells of macrophage and fibroblast-like morphology respectively. The macrophage-like cells had a few scattered microvilli and surface ruffles on their dorsal (upper) surface and rounded or folded pseudopods, which were flattened against the bone surface. Small, widely spaced retraction fibres extended from the cell margin and bound the cells to the bone surface. In cell cultures derived from all synovial samples which contained bone fragments, occasional large cells (up to $150 \mu \mathrm{m}$ ) of osteoclast-like morphology were also noted. On their dorsal surface these cells had considerably more microvilli, which were tightly concentrated over a central dome-like area. In addition, they had occasional surface ruffles and a broad cytoplasmic outline with closely spaced retraction fibres.

Two patterns of bone resorption were noted in cell cultures on bone slices. Typical lacunar resorption pits were seen after 24 hours and three days of incubation of cells derived from synovial samples which on histological examination were found to contain bone fragments (fig 4) (table 2). The absolute number of resorption pits and surface area of bone resorbed was increased in longer term (7-28 day) cultures, though this phenomenon was not uniform, possibly indicating individual differences in the number and nature of bone resorbing cells seeded onto each bone slice or the viability of such cells. Analysis of cells cultured on glass coverslips incubated in parallel with those which produced lacunar resorption pits on bone slices after 24 hours and three days showed that they included osteoclast-like giant cells in the 
cell isolates; such giant cells were tartrate resistant acid phosphatase positive, calcitonin sensitive, and did not express CD1la/18 and CD14. It was therefore concluded that lacunar resorption pits were formed by osteoclasts or osteoclast-like cells which had been isolated from the synovial membrane where they formed a physiological response to bone and calcific fragments deposited in the membrane as products of a degenerative arthritis, either primary (as in OA) or secondary (as in RA).

In patients with RA and, to a lesser extent, $O A$, a second type of bone resorption was noted. This was first seen in three day cultures but was most pronounced and of greater extent in longer term cultures (longer than seven days) after the cells had been removed with aqueous ammonia. On these bone slices there were poorly defined small and large areas of roughening of the bone surface with exposure of mineralised collagen fibres (fig 5). These were commonly found around small and large cells either isolated or more often in groups, and also fairly often at the edges of resorption pits. Such surface roughening or resorption was seen in cultures derived from all samples from patients
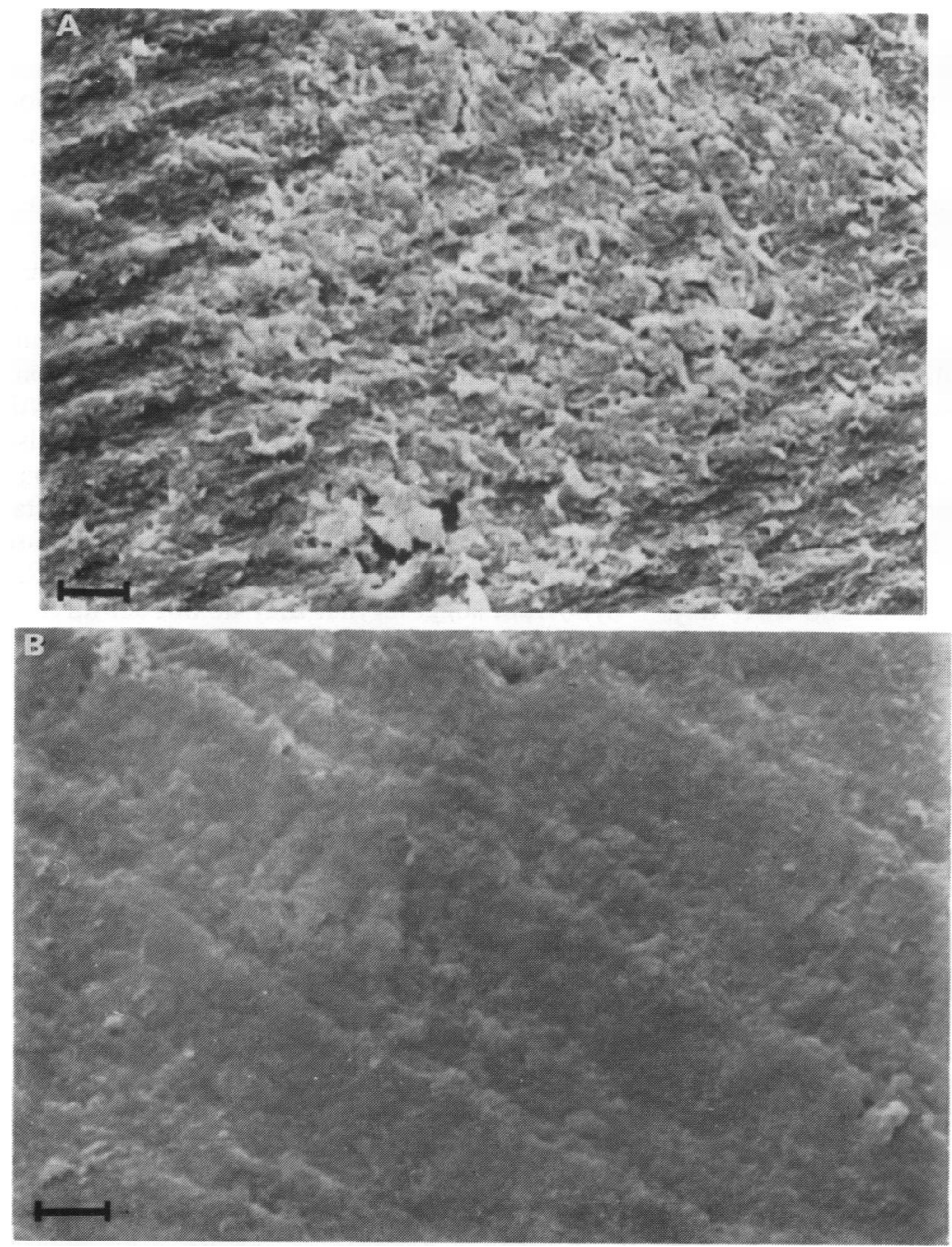

Figure 5 (A) Superfictai resorption of bone surface seen after removal of cells derived from synovium of a patient with rheumatoid arthritis incubated for 14 days on bone slices. This shows an area of roughening of the bone surface without resorption pit formation and unresorbed bone surface (left). Bar $=10 \mu \mathrm{m}$. (B) Control bone slice on which no cells had been settled showing smooth bone surface. Bar $=10 \mu \mathrm{m}$. with $\mathrm{RA}$, including those which did not contain bone fragments and were thus not associated with lacunar resorption pit formation. Surface roughening was more pronounced in cell cultures derived from patients with RA than in those from patients with $O A$, and was particularly notable in those cultures from patients with RA containing large numbers of macrophage-like cells.

The addition of local and systemic hormones known to stimulate bone resorption (parathyroid hormone, 1,25-dihydroxy vitamin $\mathrm{D}_{3}$, interleukin 1 , and prostaglandin $E_{2}$ ) did not lead to an increase in resorption pit formation in those cultures containing osteoclasts (table 2), nor did the addition of hormones to the cultures of cells from patients with RA which did not produce resorption pits on bone slices induce such cells to form osteoclast-like resorption pits. Calcitonin did not inhibit either lacunar or surface resorption. The effect of hormones on surface roughening was difficult to evaluate as, although present in all long term (longer than seven days) cultures of cells derived from patients with RA, the extent of such surface resorption varied between different RA samples and followed no clear pattern of hormonal stimulation or inhibition.

\section{Discussion}

This study has identified and characterised two forms of bone resorption associated with two distinct cell types in the RA synovial membrane. Lacunar resorption pits were seen early in some cell cultures derived from RA synovium (and all $\mathrm{OA}$ derived synovia) where bone and calcified fragments were present in the synovium and these appear to have been due to the presence of osteoclasts. A low grade type of bone resorption, characterised by roughening of the bone surface around mononuclear and multinucleated cells identified as macrophages and macrophage polykaryons respectively, was also prominent in all cultures of cells derived from RA synovium, particularly in those incubated for prolonged periods. Systemic and local hormonal factors do not appear to influence this low grade bone resorption greatly.

Most of the phagocytic cells isolated from the rheumatoid synovial membrane were macrophages. These cells adhered to glass coverslips, ${ }^{19}$ did not respond to calcitonin, ${ }^{18}$ expressed monocyte/macrophage antigens CD68, CD1 $1 \mathrm{a} / 18$, and CD14, ${ }^{16}$ and were initially acid phosphatase positive and tartrate resistant acid phosphatase negative. Although many of these mononuclear macrophages fused in vitro to form tartrate resistant acid phosphatase positive multinucleated cells, neither multinuclearity nor tartrate resistant acid phosphatase staining can be regarded as a reliable marker for osteoclast differentiation in culture, this being equally associated with macrophage polykaryon formation. ${ }^{20}$ The number of macrophages isolated from $\mathrm{RA}$ synovium was greater than that from OA synovium and this was reflected in the increased amount of surface resorption on bone slices containing cell cultures derived from RA synovium. Surface resorption was 
equally evident in those cell cultures from RA synovium which did not contain bone fragments and was more pronounced in longer term (more than seven day) cultures. These features indicate that this type of bone resorption is not due to osteoclasts and is a property of the inflammatory macrophages within the synovial membrane. Mononuclear phagocytes bind to mineralised bone matrix. ${ }^{21}$ There is considerable indirect evidence, largely from the release of radiolabelled calcium and proline from devitalised bone particles, that monocytes, ${ }^{22}$ macrophages, ${ }^{10}$ and their fused products $^{11}$ are capable of degrading the organic and inorganic components of the bone matrix. Extensive surface resorption by mononuclear phagocytes may represent the morphological correlate of this phenomenon. In support of this there have been several studies which have shown that macrophages and macrophage polykaryons derived from inflammatory lesions and extraskeletal tumours containing large numbers of these cells also show this low grade type of bone resorption. ${ }^{12} 1323$ Stromal cells, such as fibroblasts and osteoblasts, cultured alone under similar conditions on bone slices have not been associated with this phenomenon. ${ }^{13} 24-26$

Lacunar resorption pit formation on bone slices appears to have been due to the activity of a small number of osteoclasts which were present in our cultures. Osteoclasts were identified on the basis of their characteristic response to calcitonin, positive tartrate resistant acid phosphatase activity in multinucleated cells present in early cultures, and restricted expression of macrophage associated antigens. Their presence in cell cultures derived from four patients with RA and all patients with OA can be explained by the fact that synovia derived from all these patients contained, on histological examination, bone debris with an associated osteoclastic response. Such bone particles are commonly found embedded in the synovium as a consequence of a primary or secondary degenerative arthritis. ${ }^{27}$ Characteristic of osteoclastic bone resportion, such lacunar resorption pits were seen in early ( 24 hour and three day) cultures. ${ }^{28}$ They were not greatly increased in longer term (more than seven days) cultures, suggesting that they were due to the activity of a few osteoclasts in cells from RA and OA synovium. Although lacunar bone resorption was formerly regarded as a property of osteoclasts alone, ${ }^{29}$ it has now been shown that murine monocytes and tissue macrophages can differentiate in vitro into cells capable of this specialised function. ${ }^{30}{ }^{31}$ This differentiation of mononuclear phagocytes into high grade bone resorbing cells takes 14 days to complete, however, at which time the first resorption pits are formed. This process is thus unlikely to account for the resorption pits observed early in our cultures.

Marginal erosions are a common consequence of RA; they develop over a variable time span generally measured in months or years depending on the joint affected, the stage and severity of rheumatoid inflammation, and the treatment administered. ${ }^{32} 33$ Rheumatoid synovium and pannus is composed of a mixture of inflammatory cells including numerous mononuclear phagocytes $^{5}$; these consist of subintimal tissue macrophages and type A synovial lining cells. Although the nature of the cells in pannus which cause articular tissue destruction has not been clarified, this study has shown that macrophages are capable of a type of low grade bone resorption. Individually, macrophages appear to resorb considerably less than osteoclasts, but collectively their contribution to the osteolysis of erosive RA is likely to be of quantitative importance due to the large number of macrophages present in the rheumatoid inflammatory milieu. The fact that such macrophage mediated bone resorption is not as dramatic as that associated with osteoclasts agrees well with the known clinical pattern of development of marginal erosions in RA.

Osteoclastic bone resorption is nevertheless evident histologically in erosive RA and is likely to be the major cellular mechanism accounting for the development of larger lytic lesions and rapid erosive changes in advanced RA. This may be superimposed on a background of low grade macrophage mediated bone degradation. Macrophages may also promote osteoclast mediated bone resorption by secretion of collagenase by activated macrophages in RA; this would allow increased osteoclastic contact with bone mineral, the latter being the stimulus that initiates osteoclastic bone resorption. ${ }^{34}$ Inded, the appearance of surface resorption under a scanning electron microscope is not morphologically dissimilar to that of the surface of cortical bone slices after prolonged protease (trypsin or collagenase) treatment.

Macrophage products known to act as local mediators in the inflammation and joint destruction of RA include prostaglandins and cytokines such as interleukin 1, tumour necrosis factor $\alpha$, and transforming growth factor $\beta .^{5633} 35$ Such local factors are also known to stimulate osteoclastic bone resorption. ${ }^{78}$ The fact that interleukin 1 and prostaglandin $\mathrm{E}_{2}$ did not obviously upgrade or increase resorption by macrophages derived from RA synovium suggests that they do not act directly on these cells and that their major effect may be on osteoclastic bone resorption. It is likely that too few osteoclasts were present in our cultures to observe such an effect. Moreover, these factors act indirectly on osteoclasts via the stimulation of osteoblasts, which would be absent from our cultures. ${ }^{78}$ For the same reasons, parathyroid hormone and 1,25dihydroxyvitamin $\mathrm{D}_{3}$, systemic hormones known to affect bone resorption, do not appear to influence either low or high grade resorption by cells derived from RA synovium. Calcitonin is known to inhibit osteoclastic activity and bone resorption directly, although 'escape' from its effect does occur. Calcitonin did not affect macrophage mediated low grade bone resorption or the high grade lacunar bone resorption of osteoclasts.

A further possible means whereby macrophages could affect lacunar bone resorption follows from experiments which show that it is possible for human and murine tissue macrophages derived from primary (extraskeletal) 
tumours and inflammatory foreign body lesions to develop into high grade bone resorbing polykaryons in an appropriate stromal cell and hormonal microenvironment. ${ }^{36} 37$ Clearly, if such stromal and hormonal elements are present in rheumatoid pannus then these could promote a macrophage associated mechanism of extensive and rapid bone destruction.

We thank Miss $\mathbf{L}$ Watts for typing the manuscript. This work was funded in part by the Cancer Research Campaign. The interleukin $1 \alpha$ was kindly provided by Dr J Saklatvala.

1 Gardner D L. The pathology of rheumatoid arthritis. London: Edward Arnold, 1972.

2 Edwards J C W. The origin of type A synovial lining cells. Immunobiology 1982; 161: 227-31.

3 Athanasou $\mathbf{N}$ A, Quinn J $M$ W. Immunocytochemical analysis of human synovial lining cells: phenotypic relationship to other marrow-derived cells. Ann Rheum Dis 1991 50: 311-5.

4 Henderson B, Revell P A, Edwards J C. Synovial lining cell hyperplasia in rheumatoid arthritis: dogma and fact. Ann Rheum Dis 1988; 47: 348-9.

5 Zvaifler N J. Etiology and pathogenesis of rheumatoid arthritis. In: McCarty D J, eds. Arthritis. Philadelphia: Lea and Febiger, 1979; 557-70.

6 Cush J J, Kipsky P E. Cellular basis for rheumatoid inflammation. Clin Orthop 1991; 265: 9-22.

7 Marks S C, Popoff S N. Bone cell biology: the regulation of development, structure and function in the skeleton. $A m \mathcal{F}$ development, structure

8 Mundy G R, Roodman G D. Osteoclast ontogeny and function. In: Peck W A, ed. Bone and mineral research. Vol. 5. Amsterdam: Elsevier, 1987: 209-79.

9 Nathan C F. Secretory products of macrophages. $7 \mathrm{Clin}$ Invest 1987; 79: 319-26.

10 Teitelbaum S L, Stewart C C, Kahn A J. Rodent peritonea macrophages as bone resorbing cells. Calcif Tissue Int 1979, 27: 255-61.

11 Fallon M D, Teitelbaum S L, Kahn A J. Multinucleation enhances macrophage mediated bone resorption. Lab Invest 1983; 49: 159-64.

12 Athanasou N A, Wells C A, Quinn J, et al. The origin and nature of stromal osteoclast-like giant cells in breast nature of stromal osteoclast-like giant cells in breast carcinoma: implications for tumour osteolys

13 Athanasou N A, Quinn J, Ferguson D, McGee J O'D. Bone resorption by macrophage polykaryons of a giant cell resorption by macrophage polykaryons of a giant cell

14 Arnett P C, Edworthy S M, Bloch D A, et al. The American Rheumatism Association 1987. Revised Criteria for the Classification of Rheumatoid Arthritis. Arthritis Rheum 1988; 31: 315-24.

15 Minkin C. Bone acid phosphatase: tartrate-resistant acid phosphatase as a marker of osteoclast function. Calcif Tissue Int 1982; 34: 285-90.

16 Athanasou N A, Quinn J. Immunophenotypic differences between osteoclasts and macrophage polykaryons: immunohistological distinction and implications for osteoclast ontogeny and function. F Clin Pathol 1990; 43: 997-1003.

17 Knapp W, Doerken K, Gilks W R, et al. eds. Leucocyte typing IV. Oxford: Oxford University Press. 1989.

18 Chambers T J, Magnus C J. Calcitonin alters behaviour of isolated osteoclasts. $\mathcal{F}$ Pathol 1982; 136: 27-39.

19 Cohn Z A Benson B. The differentiation of mononuclear phagocytes. $\mathcal{F} \operatorname{Exp} M$ ed 1965; 121: 153-9.

20 Hattersley G Chambers T J. Generation of osteoclastic function in mouse bone marrow cultures: multinuclearity and tartrate-resistant acid phosphatase are unreliable markers for osteoclastic differentiation. Endocrinology 1989; 124: $1689-96$.

21 Kahn A J, Stewart C C, Teitelbaum S L. Contact mediated bone resorption by human monocytes in vitro. Science 1978; 199: 988-90.

22 Mundy G R, Altman A J, Gondek M D, Bandedlin J G. Direct resorption of bone by human monocytes. Science 1977; 196: 1109-21.

23 Athanasou N A, Quinn J, Bulstrode C J. Resorption of bone by inflammatory cells derived from the artificial joint capsule of revision hip arthroplasties. $\mathcal{F}$ Bone foint Surg capsule of revision hip

24 Jones S J, Boyde A. Colonization of various natural substrates by osteoblasts in vitro. In: O'Hare III, A M F, ed. Scanning electron microscopy. Chicago, IL: SEM Inc, 1979: 529-38.

25 McSheehy P M J, Chambers T J. Osteoblastic cells mediate osteoclastic responsiveness to parathyroid hormone. Endocrinology 1986; 118: 824-8

26 Thomson B M, Saklatvala J, Chambers T J. Osteoblasts mediate interleukin-1 stimulation of bone resorption by rat osteoclasts. $\mathcal{F} \operatorname{Exp}$ Med 1986; 164: 104-12.

27 Fassbender H G. Pathology of rheumatic diseases. Berlin, Springer Verlag, 1975.

28 Chambers T J, Revell P A, Fuller K, Athanasou N A. Resorption of bone by isolated rabbit osteoclasts. $\mathcal{F}$ Cell Sci 1984; 66: 383-99. 29 Chambers T J, Horton M A. Failure of cells of the mononuclear phagocyte series to resorb bone. Calcif Tissue Int 1985; 36: 556-9.

30 Udagawa N, Takahashi N, Akatsu T. Origin of osteoclasts: mature monocytes and macrophages are capable of differentiating into osteoclasts under a suitab prepared by bone marrow-derived stromal cells. Proc Natl Acad Sci USA 1990; 87: 7260-4.

31 Quinn J M, Athanasou N A. Tumour infiltrating macrophages are capable of bone resorption. 7 Cell Sci 1992; 101: 681-6.

32 Berens D L, Lin $\mathbf{R}$ K. Roentgen diagnosis of rheumatoid arthritis. Springfield: Thomas, 1969.

33 Harris E D. Rheumatoid arthritis: Pathophysiology and implications for therapy. $N$ Engl $\mathcal{f}$ Med 1990; 322: implications.

34 Chambers T J, Thomson E M, Fuller K. Effect of substrate composition on bone resorption by rabbit osteoclasts. $\mathcal{F}$ Cell

35 Robinson D R, Tashjian A H, Levine L. Prostaglandinstimulated bone resorption by rheumatoid synovia. $\mathcal{f}$ Clin Invest 1975; 56: 1181-8.

36 Athanasou N A, Quinn J M. Human tumour-associated macrophages are capable of bone resorption. $\mathrm{Br} \mathcal{F}$ Cancer 1992; 65: 523-5.

37 Quinn J M, Joyner C J, Triffit J T, Athanasou N A. Polymethyl methacrylate-induced inflammatory macrophages resorb bone. $\mathcal{f}$ Bone foint Surg [Br]. In press. 